\title{
En busca de un marco teórico empíricamente fundado para el análisis comparado de la colonialidad en las trayectorias migratorias de mujeres del Sur. Notas de investigación
}

\section{Searching an empirically founded theory for the comparative analysis of coloniality in the migratory trajectories of women from the South. Research Notes}

\author{
Andrea Souto García \\ andrea.souto@udc.es \\ Equipo de Investigación Sociedades en \\ Movimiento. Universidade de La Coruña, España
}

\section{María Eugenia Ambort \\ maruambort@gmail.com \\ Centro Interdisciplinario de Metodología de las Ciencias Sociales. Instituto de Investigaciones en Humanidades y Ciencias Sociales (IdIHCS - CONICET). Universidad Nacional de La Plata, Argentina}

\section{Recepción: 26 Mayo 2020 \\ Aprobación: 22 Octubre 2020 \\ Publicación: 01 Febrero 2021}

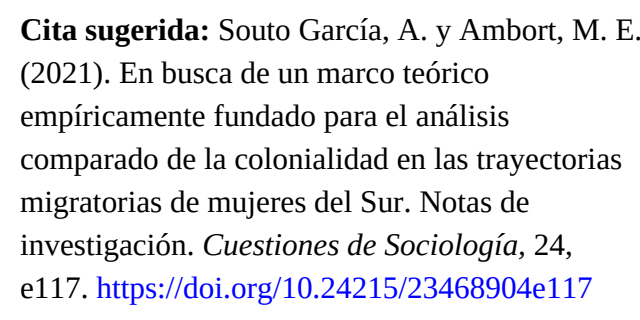

Resumen: Este trabajo tiene por objetivo discutir la posibilidad de la comparación respecto de la desigualdad social entre América Latina y Europa, partiendo de dos investigaciones empíricas en curso. Ambas investigaciones tienen en común el estudio de trayectorias de mujeres migrantes. Mujeres que han dejado sus lugares de origen para transitar caminos que les permitan forjar "una mejor vida". Estos desplazamientos están marcados por la globalización neoliberal, por la precariedad a la deriva y la búsqueda de horizontes en países que les ofrecen, en principio, mejores (o algunas) oportunidades. Con estas notas de investigación pretendemos incorporar la mirada post/decolonial, interseccional y feminista en los estudios cualitativos comparados, sustentando con historias de vida el análisis de la tensión entre estructura y agencia social. En primer lugar, presentamos dos narrativas donde describimos los trabajos de campo de nuestras investigaciones doctorales. A continuación, retomamos elementos de ambos relatos para ir entrelazando categorías que, de manera comparada, permitan reflexionar sobre la forma en que se reconfiguran los vínculos coloniales y la estructura patriarcal en el entramado de trayectorias vitales que dan lugar a las migraciones de mujeres del Sur hacia el Norte global.

Palabras clave: Colonialidad, Interseccionalidad, Género, Migraciones, Estudios Comparados.

Abstract: This paper aims to discuss the possibility of comparison
regarding social inequality between Latin America and Europe,
using as main input two empirical researches in progress. Both
investigations have in common the study of migrant women's
trajectories. Women who have left their places of origin to travel
paths that allow them to forge "a better life." These movements are
marked by neoliberal globalization, by adrift precariousness and
the search for horizons in countries that offer them, in principle,
better (or some) opportunities. With these research notes we
intend to incorporate the post/decolonial, intersectional and
feminist gaze in comparative qualitative studies, supporting with 


\begin{abstract}
life stories the analysis of the tension between structure and social agency. First, we present two narratives where we describe the fieldwork of our doctoral researches. Next, we take up elements of both narratives to intertwine categories that, in a comparative way, allow us to think about how colonial ties and patriarchal structures are reconfigured among the life trajectories of women from the South that immigrate towards the global North.
\end{abstract}

Keywords: Coloniality, Intersectionality, Gender, Migrations, Comparative Studies.

\section{Introducción}

Este trabajo tiene por objetivo poner en común y discutir la posibilidad de la comparación respecto de la desigualdad social entre América Latina y Europa, partiendo de dos investigaciones empíricas en curso, y que esperan dar lugar a las tesis doctorales de quienes escriben.

América Latina y Europa son realidades disimétricas, identidades geopolíticas inseparables que emergen y se desarrollan a partir de una historia común. Los regímenes de sentido instaurados a uno y otro lado del Atlántico, desde ese lugar que es la Historia, han sido el soporte de las desigualdades múltiples y abismales que se abren hoy día entre ambos continentes, pero también al interior de los mismos (De Sousa Santos, 2014). Estos regímenes han dado lugar a categorías de estratificación social que configuran los imaginarios colectivos y trazan horizontes de vida, lo que permea de modo inexorable las experiencias de las personas, de las comunidades que surgen en el tránsito de ese espacio social transoceánico y continuo que es América Latina y el sur de Europa, o lo que ha dado en llamarse "Iberoamérica".

Ambas investigaciones se desarrollan en el marco de la red INCASI, ${ }^{1}$ con puntos de referencia a uno y otro lado del Atlántico, y tienen en común el estudio de trayectorias de mujeres migrantes. Mujeres que han dejado sus lugares de origen para transitar caminos que les permitan forjar "una mejor vida", o simplemente dar un giro a la realidad en la que vivían antes de migrar, para ellas o para sus hijos e hijas. Con más o menos margen de libertad, y cada uno en su singularidad, estos desplazamientos están marcados por la globalización neoliberal (Mezzadra y Nielson, 2013), por la precariedad a la deriva (PérezOrozco, 2014) y por la búsqueda de horizontes en países que les ofrecen, en principio, mejores (o algunas) oportunidades. Decimos "marcados por la globalización", porque, efectivamente, este dispositivo que casi todo lo rige, llamado capitalismo global/neoliberal (Ehrenreich y Hochschild, 2003), no es solo una forma discursiva de entender el mundo en que vivimos, sino que encuentra carnadura en los cuerpos, en los rostros, en los paisajes, en la sonoridad de los lenguajes, en las manos que trabajan, en los hijos e hijas nacidas a un lado $\mathrm{u}$ otro de las fronteras. Y, obviamente, define la estructura de oportunidades que cada sujeto encuentra, exige o se inventa, para vivir y sobrevivir, en origen y en destino (Sayad, 1996). Estas marcas, que no se reducen a -pero que sí se condensan en- categorías como el género, la raza y la clase (Winker \& Degele, 2011) exigen abrir el paraguas de la interseccionalidad (Crenshaw, 1989; Hill 
Collins, 2017; Hill Collins y Bilge, 2016) para comprender las desigualdades en su multidimensionalidad (Reygadas, 2004).

La red INCASI es un proyecto impulsado desde universidades de la Unión Europea, que pone en diálogo 10 equipos de investigación de Europa y 10 de América Latina para el análisis comparado de las desigualdades sociales. En su primera etapa (2017-2019), se destacó por el armado del marco teóricometodológico que diera pie a la investigación, y por propiciar la movilidad entre continentes de becarios/as e investigadores/as para generar las articulaciones necesarias y las condiciones para producir conocimiento in situ. Este ejercicio comparado forma parte de los cruces que esta red, con sus intercambios, permitió construir. Desde una mirada reflexiva del proceso de investigación (Bourdieu, 2003; Gregorio, 2019), el acto de ponerle el cuerpo a estos viajes, aunque no fuera en calidad de migrantes (y salvando las distancias), permitió poner en tela de juicio y vivir en primera persona la experiencia de la alteridad en el extranjero.

Los estudios de caso, empíricos y cualitativos, analizan en profundidad aspectos puntuales de la realidad social con el objetivo de comprender problemáticas sociales más globales y sus dinámicas (Neiman y Quaranta, 2006). Las migraciones indefectiblemente ponen en relación territorios y pueblos que se encuentran y entrelazan tramos de la historia (Portes, 2009). El trasfondo del capitalismo global transnacionalizado, heredero de los colonialismos europeos sobre América, Asia y África, es la estructura sobre la que se organizan las relaciones de desigualdad (en continua reproducción) entre el Norte y el Sur global$^{2}$ (Wallerstein, 1997).

Estas notas de investigación pretenden ser un ejercicio que nos permita incorporar la mirada post/decolonial, interseccional y feminista en los estudios cualitativos comparados, sustentando con historias de vida el análisis de la tensión entre estructura y agencia social (Bourdieu, 2000). En primer lugar, presentamos dos narrativas donde describimos los trabajos de campo de nuestras investigaciones doctorales. A continuación, retomamos elementos de ambos relatos para ir entrelazando categorías que, de manera comparada, permitan reflexionar sobre la forma en que se reconfiguran los vínculos coloniales y la estructura patriarcal en el entramado de trayectorias vitales que dan lugar a las migraciones de mujeres del Sur hacia el Norte global.

\section{Cuerpos racializados, cuerpos disponibles: relatos de investigación sobre mujeres que migran desde el Sur global.}

Este trabajo compara las migraciones de mujeres bolivianas a la Argentina y de brasileñas y colombianas a Portugal y España, mostrando las diversas maneras en que el régimen de poder neoliberal, patriarcal y colonial se inscribe en los cuerpos de las migrantes pobres del Sur en el Norte (Gregorio, 2017; Magliano, 2015). Las posiciones geoculturales son, como las identidades a que dan lugar, relaciones dialécticas (De Sousa Santos, 2014). Cuando hablamos de Norte y Sur global nos referimos a posiciones de poder y a la representación de las sociedades de destino como exponentes de la civilización occidental, el progreso y la posibilidad de ascenso social. Así es representada Argentina respecto a Bolivia, del mismo modo que España y Portugal para Colombia y Brasil. Los procesos de racialización diferenciada (Nagel, 2003) a que son sometidas bolivianas, 
brasileñas y colombianas a lo largo del espacio social migratorio (Magliano, 2009; Wade, 2003) las configuran en clases particulares de trabajadoras, lo que condiciona inexorablemente sus trayectorias biográficas.

\section{Colombianas y brasileñas que migran a España y Portugal}

Esta investigación aborda las migraciones de mujeres brasileñas y colombianas en la Península Ibérica. Entre 2017 y 2019, en un trabajo de campo multisituado entre Porto, Madrid, Galicia y São Paulo, se realizaron 40 entrevistas a mujeres colombianas y brasileñas con experiencia migratoria en Portugal y España respectivamente. Las trayectorias de estas mujeres, llegadas en diferentes momentos desde distintos lugares geográficos y biográficos, revelan, sin embargo, disposiciones estructurales que tienden a homogeneizar sus vivencias en tanto migrantes coloniales (Grosfoguel y Maldonado-Torres, 2008).

La conformación de España y Portugal como territorios de inmigración es un fenómeno reciente. Durante 500 años, la realidad migratoria de España y Portugal ha estado marcada por la salida de grandes masas poblacionales en dirección a América (Oso y Catarino, 2013). Esto es relevante porque la forma en que las migrantes latinoamericanas son retratadas en los imaginarios nacionales portugués y español (Piscitelli, 2008; Hurtado Sáa, 2018) se ancla justamente en esos cinco siglos de historia íntima compartida, y en los sistemas específicos de explotación impuestos por los colonizadores sobre las poblaciones nativas y africanas traficadas (Quijano, 2014).

El desarrollo de las migraciones desde Brasil y Colombia, hacia España y Portugal, comienza a finales de la década de los 90, con la integración "completa" de los dos países a la Unión Europea (Oso y Catarino, 2013). Con el auge del neoliberalismo a nivel global, las economías del sur de Europa se terciarizan, y pasan de una economía centrada en la producción hacia una economía de servicios (Actis, 2009; França y Padilla, 2018). La expansión de los mercados precarizados de trabajo que sucedió a este proceso abrió las puertas a la emergencia de una nueva clase de proletariado: la mujer migrante del Sur global (Ehrenreich y Hochschild, 2003; Sassen, 2003).

Los contingentes brasileños y colombianos llegados a Portugal y España tienen un marcado carácter femenino, porque la oferta laboral disponible en dichos mercados nacionales es comprendida como una suerte de destino social para este perfil concreto de mujeres (Oso y Parella, 2012; Vélez de Castro y Cravidão, 2010). Y también, porque en la otra orilla de esta historia, ante las crisis sociales cíclicas generadas por los Programas de Ajuste Estructural (Sassen, 2003), las mujeres brasileñas y colombianas se han cargado a sus espaldas la supervivencia de sus familias y comunidades. En este sentido, la migración es producto de las transformaciones macroeconómicas que asedian la vida, pero también es una reacción de resistencia femenina; una estrategia de sobrevivencia colectiva que las mujeres, espoleadas por el mandato de género, llevan adelante (Federici, 2013).

Las mujeres protagonistas de esta historia provienen mayoritariamente de las clases populares que habitan las áreas suburbanas de Cali, Bogotá, Pereira y Risaralda en Colombia, y São Paulo, Curitiba, y Rio de Janeiro en Brasil. Muchas de ellas son solteras o separadas, muy frecuentemente madres abandonadas por los padres de sus hijos e hijas, que, en busca de un futuro mejor, toman el camino 
de la migración, no solo como alternativa de subsistencia, sino también como un proyecto de emancipación personal. La articulación de redes transnacionales de colaboración y cuidado femeninas (Pedone, 2010) ha sido clave para la emergencia de estas migraciones de mujeres solas, que casi siempre se ven forzadas a dejar atrás a sus hijos e hijas al cuidado de abuelas, tías y vecinas (Gregorio, 2017; González Torralbo, 2016). Otras son mujeres jóvenes, solteras, quienes, ante la situación de invivilidad desatada en los contextos de origen por la violencia y la falta de oportunidades, ven en los países "desarrollados" la promesa de una buena vida.

Estas migrantes llegan a la Península Ibérica para ser empleadas en aquellos nichos laborales más desprestigiados desde el punto de vista social y económico: el servicio doméstico, el cuidado de personas, otras actividades precarias del sector servicios, y también la prostitución (Hurtado Sáa, 2018; Torralbo, 2016). La ilegalidad, al menos en los comienzos, y el deber de enviar periódicamente dinero a las familias remanentes en origen son variables comunes de estas experiencias migratorias (França y Padilla, 2018; Oso y Suárez-Grimalt, 2018), que hacen de ellas aventuras marcadas por el extremo riesgo y sacrificio que asumen las mujeres que se atreven a emprenderlas. El envío de remesas, sostenido en ocasiones durante décadas e incluso después de la reagrupación de los hijos e hijas, es una expresión del compromiso de las migrantes para con sus seres queridos (Pedone, 2010).

La colonialidad subyacente en los modos en que son construidas las identidades migratorias (Grosfoguel y Maldonado-Torres, 2008) de brasileñas y colombianas y su repercusión en los procesos de inserción sociolaboral en las sociedades de destino determinan sus trayectorias migrantes en Portugal y España. Para la población local estas mujeres encarnan, por medio de su nacionalidad, "lo latino". Se hace notoria la centralidad de lo negro, en tanto marca racial, en esta forma de identificación, al ser justamente aquellas procedentes de Estados afrodescendientes las habilitadas como representantes adecuadas de la latinidad. Los estereotipos que entran en juego a partir de dicha categorización -la avidez sexual, acompañada de una personalidad desenfadada y complaciente- acaban por encerrar a estas mujeres en ubicaciones inseguras en las sociedades de destino (Nagel, 2003; Piscitelli, 2008).

En las sociedades capitalistas, quién se es tiene que ver con qué trabajos se desempeñan. El estatus social se construye a partir del ejercicio simbólico y material de prácticas sociolaborales (Bourdieu, 2000). Si, como otras mujeres migrantes, colombianas y brasileñas se emplean habitualmente en el servicio doméstico y de cuidados, es destacable su presencia mayoritaria en los mercados sexuales en expansión. España es el décimo país del mundo en el ranking de destinos de turismo sexual, y, en los prostíbulos de esta frontera europea, brasileñas y colombianas son las nacionalidades más comunes (Piscitelli, 2008; Hurtado Sáa, 2018). La forma en que son imaginadas por los varones locales produce un "efecto demanda" de esta raza particular de mujeres a las que se les presupone un saber-hacer natural para la producción de placer.

En ocasiones, las mujeres son capaces de subvertir el racismo que constriñe sus experiencias migratorias, y lo hacen jugar en su favor, para situarse mejor dentro de los mercados laborales y matrimoniales. La preeminencia de lo estético en la identidad "mujer" y "brasileña/colombiana", lo atractivo inherente a la misma 
(en un determinado mercado de belleza), puede promover movilidades sociales ascendentes (Malheiros y Padilla, 2015). Así, las mujeres que logran rentabilizar eficientemente su "capital racial" consiguen emplearse en actividades tales como la restauración y el comercio, que requieren trato directo con el público y que tienen generalmente mejores condiciones que las que se encuentran en el servicio doméstico y de cuidado (Malheiros y Padilla, 2015).

Esta entrada a espacios laborales más abiertos al público, generalmente ámbitos de influencia masculina, las hace más visibles y en cierto modo más asequibles para los varones autóctonos. Brasileñas y colombianas son, de entre todas las migrantes presentes en Portugal y España, las más proclives a participar de un matrimonio mixto en estos países. ${ }^{3}$ Aunque el enlace matrimonial con un local puede ser entendido como otra forma de capitalización de los prejuicios racistas que enfrentan, la pertenencia a este "club de las primeras esposas", entraña, sin embargo, ciertos riesgos para las migrantes. El matrimonio puede suponer el camino más rápido a la regularización, con las ventajas económicas y políticas que ello acarrea, tales como la posibilidad de salir de la informalidad laboral o la aceleración de los procesos de reagrupamiento de los hijos e hijas. Pero la desigualdad abismal que se abre entre les cónyuges en este tipo de uniones, amparada por las leyes migratorias, coloca a las mujeres en situaciones de vulnerabilidad extrema (Piscitelli, 2011; 2008). Así, a lo largo de sus trayectorias migratorias, las mujeres brasileñas y colombianas en Portugal y España, atrapadas entre las representaciones culturales, las leyes de migración y el deber que les impone su condición femenina, son objeto recurrente de violencias múltiples.

\section{Bolivianas que migran a la Argentina}

En esta investigación reconstruimos las historias de vida de mujeres de origen boliviano que actualmente viven y trabajan en la agricultura en Argentina. Realizamos 25 entrevistas biográficas en profundidad, en las que las invitamos a reconstruir sus trayectorias familiares, laborales y migratorias. El trabajo de campo se realizó entre 2017 y 2019 en el cinturón hortícola del gran La Plata (Buenos Aires), una de las regiones de producción de hortalizas más importantes del país, y donde las familias bolivianas son las principales responsables de los establecimientos (García, 2011).

Las mujeres que entrevistamos nacieron en distintas regiones de Bolivia, en comunidades rurales muy empobrecidas, y llegaron a la Argentina, ya fuera de pequeñas (con sus padres) o de jóvenes-adultas, algunas solteras, y la mayoría luego de haber formado una pareja. Sus familias de origen eran campesinas, y producían para la subsistencia. La mayoría de ellas se inserta en lo que Cassanello ha denominado una "cultura migratoria" (2014). Es decir, migrar forma parte de las expectativas en términos de desarrollo individual, familiar y comunal, ya que varias generaciones (sobre todo de familias campesinas sin tierra) se han trasladado de una región a otra dentro de Bolivia, y también hacia países limítrofes. Este origen social, atravesado por todo tipo de carencias materiales (hambre, frío) y sacrificios, hacía de la migración de los hijos e hijas, a medida que iban creciendo, una estrategia familiar de supervivencia. Así, era común que (fundamentalmente las hijas mujeres) abandonaran la escuela en los primeros años de primaria para mudarse a pueblos cercanos y trabajar como empleadas 
domésticas o niñeras cama adentro. Esto significaba algunos ingresos extra para la familia, pero sobre todo una boca menos para alimentar.

Para estas mujeres, migrar forma parte de un proyecto fundamentalmente familiar, que está asociado a las formas de organizar el trabajo en la producción campesina, con una fuerte interdependencia de sus miembros (Chayanov, 1974). Si bien en muchos análisis sobre la agricultura familiar solo se considera al jefe del hogar como "productor", y al trabajo de su familia como "ayudas", los estudios que incorporan la perspectiva de género recuperan el lugar (muchas veces invisibilizado) de las mujeres, tanto en el trabajo de la tierra como en el trabajo doméstico y de cuidados, que les es asignado de forma naturalizada en la división sexual del trabajo (Deere, 1982; Agarwal, 2002).

Argentina es el principal destino migratorio de Bolivia, ${ }^{4}$ y en todas las historias de vida que recopilamos existen antecedentes migratorios hacia este país en las familias o comunidades. Las redes tejidas por la comunidad boliviana a un lado y otro de la frontera han llevado a que sea caracterizada como transnacional (Benencia, 2005). Esta comunidad, que ya lleva varias décadas y generaciones en Argentina, se sostiene a través de una cohesión muy fuerte basada en lazos de parentesco y paisanaje, que garantizan el acceso a techo y trabajo de los/as recién llegados/as, quienes mantienen vínculos sentimentales, económicos y culturales con sus lugares de origen. Por otro lado, esta unidad entre compatriotas se relaciona con la propia segmentación étnico-racial de la sociedad argentina, vista a sí misma como fundamentalmente criolla, blanca y europea (Grimson, 2006). Las bolivianas se insertan así en nichos laborales que, en general, la población nativa no está dispuesta a ocupar, por ser precarios, demandantes de grandes esfuerzos o mal remunerados (como el textil, la agricultura o el servicio doméstico); así logran progresar a través de una intensa (auto)explotación.

A pesar de que Argentina se defina como una sociedad "que descendió de los barcos", la realidad es que las migraciones limítrofes han existido siempre, con flujos constantes de población que llega en busca de "una vida mejor". La historia (post)colonial en estas latitudes ha marcado diferencias insalvables entre ambos Estados nacionales. Argentina se constituye en el imaginario colectivo como una de las sociedades más "europeizadas" de América Latina, a partir del exterminio de los pueblos originarios, la conformación de una sociedad criolla y las estrategias de blanqueamiento, con la llegada de inmigrantes europeos desde la segunda mitad del siglo XIX (Grimson, 2006), que se suman a los procesos de urbanización e industrialización. Por otro lado, Bolivia, que fuera uno de los territorios más castigados por la invasión colonial como consecuencia de la extracción de oro y plata bajo el régimen de sometimiento indígena de la mita y la encomienda, es actualmente uno de los países más empobrecidos del continente y con mayor presencia indígena entre su población. A pesar de las transformaciones de las últimas décadas (CELAG, 2018), sigue siendo visto como un país "atrasado" y sin oportunidades de desarrollo. Las disímiles realidades socioeconómicas, acompañadas de ideas de progreso y ascenso social, son las que motivan a las mujeres bolivianas que entrevistamos a emprender el viaje migratorio. Nunca pensado como un movimiento definitivo, sino como un "tránsito" en el cual se juegan la curiosidad por lo nuevo y la búsqueda de oportunidades. Para estas mujeres, ya sea que viajen solas o acompañadas, 
la migración está enmarcada en un proyecto que involucra al grupo familiar (Magliano, 2009, Mallimaci, 2012).

Las redes sociales de la comunidad boliviana son los motores de esta migración femenina -que no feminizada-, y la mayoría de las migrantes acuden al llamado de familiares o conocidos/as para obtener sus primeros trabajos e integrarse en la sociedad de destino (Ataide, 2015). A pesar de que las leyes argentinas permiten una regularización relativamente sencilla en términos migratorios, e inclusive los hijos e hijas de inmigrantes son ciudadanos/as de pleno derecho al nacer en el país, el hecho de tener marcas físicas (rasgos indígenas, el color de la piel) o culturales (la vestimenta, la forma de hablar) supone una traba a la hora de ejercer la ciudadanía en igualdad de condiciones. La "discriminación positiva" del pueblo boliviano, como "sumiso, muy esforzado y trabajador", es la contracara de una explotación perpetua y naturalizada, que en otros sectores sociales se consideraría inadmisible (Pizarro, 2011).

Como mencionamos, el trabajo en la pequeña agricultura conlleva una fuerte interdependencia entre los miembros del grupo familiar, ya que hogar y terreno productivo generalmente quedan en el mismo lugar, y, además de convivir bajo el mismo techo, la familia trabaja junta. Esfera productiva y reproductiva se solapan y tienen límites difusos: se cuida a los/as niños/as y se realizan las tareas domésticas al mismo tiempo que se trabaja, o en los momentos de descanso. Todas las entrevistadas coinciden en que se enfrentan a una (doble) jornada laboral prácticamente sin límites, y que no poseen tiempo libre para ellas. Los roles de género naturalizados desde la primera infancia se reproducen en este período de adultez, y, por el hecho de ser madres y esposas, las mujeres son las responsables de garantizar el bienestar de toda la familia. Esta "inercia patriarcal" se presenta como un mandato naturalizado muy difícil de romper (Ambort, 2019), y es sostenida hasta por las propias mujeres, aun cuando por su trabajo no reciben remuneración, a veces ni siquiera agradecimiento (o incluso, en la convivencia, sufren violencia). El hecho de ser madres aparece como una de las mayores razones para "aguantar" este tipo de vínculos, inclusive relegando el propio deseo de regresar a Bolivia para garantizar la educación de los hijos e hijas.

En sus trayectorias laborales encontramos algunos indicios de cómo se entrenan estos cuerpos dóciles, disponibles para el cuidado y el trabajo. Inician muy tempranamente colaborando en el hogar de origen, tanto en las labores productivas como en el trabajo doméstico y cuidado de hermanos y hermanas menores. Según los testimonios, estas últimas eran fundamentales para que se convirtieran en "buenas esposas", y no eran tareas adjudicadas a sus hermanos varones. La mayoría se empleó alguna vez como empleada doméstica, y esta fue su actividad principal antes de dedicarse a la agricultura, una vez conformada su familia. Tanto en Bolivia como en Argentina se desempeñaron desde muy jóvenes como empleadas cama adentro, en condiciones cercanas a la servidumbre (con muy baja remuneración, disponibles 24 horas para cuidar o limpiar, con solo un descanso semanal, y con padecimiento de maltratos en algunos casos). Este disciplinamiento de los cuerpos, en continuidad desde los hogares propios a los ajenos, se traduce en una predisposición de las mujeres al trabajo servil. A través de las patronas - la figura femenina adulta de referencia durante su juventud-, conocieron sobre su sexualidad, los cambios físicos y las relaciones con el sexo opuesto. Una sexualidad, por cierto, plagada de tabúes, temores 
y desconocimiento sobre el propio cuerpo, que ha llevado a muchas a cursar embarazos a muy temprana edad y/o a vivir situaciones de violencia con sus parejas, sin herramientas para poder enfrentarlas.

Los patrones hegemónicos de belleza también juegan un rol importante en la inserción en la sociedad de destino de estas mujeres, ya que sus cuerpos no están categorizados dentro de "lo deseable". Existe una adscripción de "lo indio" asociado a lo frío, a lo tosco, a lo impenetrable, imágenes que remontan a la implacable cordillera andina, y que se oponen a los estereotipos "calientes" de la sensualidad afro o mulata (Canessa, 2008). Estos imaginarios sobre las mujeres indígenas alimentan las atribuciones que las caracterizan como sumisas, y reducen su humanidad a ser "buenas trabajadoras", fuerza de trabajo disponible, de bajo coste y alto rendimiento. Los patrones estéticos hegemónicos no son solo marcas que vienen "desde afuera", como estereotipos o formas de discriminación, sino que su efectividad reside en la forma en que se internalizan, minando la autoestima de estas mujeres. Sentirse fea, gorda, sucia, inculta o no lo suficientemente blanca son motivos suficientes para asumir posiciones de subalternidad.

\section{Construyendo de un marco teórico decolonial e interseccional fundado empíricamente para el estudio de las migraciones internacionales}

A continuación, retomamos elementos de ambos relatos para reflexionar de manera comparada sobre cómo colonialismo y patriarcado se reconfiguran en el entramado de trayectorias vitales que dan lugar a las migraciones de mujeres del Sur hacia el Norte global.

En las conversaciones que mantuvimos durante los encuentros INCASI acerca de nuestras investigaciones, nos dimos cuenta de que, tras la enorme diversidad de experiencias tratada en nuestros estudios subyacían ciertos elementos estructurales que nos permiten comparar las trayectorias de estas migrantes; distintas todas ellas, pero ancladas en una historia colectiva. Estos nodos comunes fueron rescatados del material empírico elaborado en nuestros respectivos trabajos de campo, a partir de las 65 entrevistas que se llevaron a cabo con mujeres migrantes bolivianas, brasileñas y colombianas en La Plata, São Paulo, Madrid, Porto y Galicia. Pero, para ser capaces de revelar y aprehender en la heterogeneidad los ejes de dominación que coaccionan la experiencia humana fue necesario antes el desarrollo de cierta mirada. Así, las ideas de otras autoras nutrieron nuestro propio modo de ver: las teorías post y decoloniales, los feminismos y la perspectiva de la interseccionalidad constituyen los lugares desde los que pensamos y anclamos a las migrantes, y también a nosotras mismas.

Las trayectorias migratorias que describimos se desarrollan en el marco de un contexto global neoliberal. El ajuste estructural, con sus consecuencias de desempleo y empobrecimiento de los sectores medios y bajos de la sociedad, y del modo particular en que se ha desarrollado en Latinoamérica, sumado a las facilidades en torno a transporte y comunicaciones brindadas por la propia globalización, favorecen la movilidad entre países, sobre todo este tipo de migraciones Sur-Norte (Mezzadra y Nielson, 2013). Más allá de las habilidades, recursos y expectativas con las que migran, las formas en que son identificadas 
en destino condicionan la manera en que estas mujeres se insertan social y laboralmente. La colonialidad subyacente a estas identificaciones explica que estos estereotipos no diverjan demasiado de la forma en que ellas se autoperciben desde los contextos de origen.

En los Estados-nacionales capitalistas, donde el valor social está dado a través de la ciudadanía y el trabajo, la inserción laboral cobra vital relevancia (Federici, 2013). Pero ser mujer, ser migrante, ser mestiza o indígena, no da igual a la hora de buscar y encontrar empleo. Tanto en Argentina, como en Portugal y en España, existen determinados nichos laborales destinados a quienes, como si estuvieran pagando un "derecho de piso", ejercen una ciudadanía de segunda por su origen social, étnico, nacional. Y también por el hecho de ser mujer. En la tensión entre formalidad-informalidad, la precariedad, la inestabilidad y la flexibilidad llevan a estas mujeres a realizar los trabajos que nadie quiere realizar, porque se consideran trabajos sucios, trabajos esforzados, y mal remunerados (Anderson, 2015; Martínez-Buján, 2014; Oso y Parella, 2012). La necesidad de conseguir ingresos rápidamente y la posibilidad de la deportación, o de quedar en evidencia como trabajadora migrante ante algún conflicto, lleva a estas mujeres a aceptar condiciones de empleo muy por debajo de lo tolerable en los países de destino. Así, estos "cuerpos sucios”, racializados, marcados por su condición de extranjeridad colonial, ocupan su lugar en los países del Norte realizando los “trabajos sucios", como la agricultura, el servicio doméstico o la prostitución, que todos rechazan, pero la sociedad toda usufructúa.

Nuestra condición de mujeres nos acerca inevitablemente a las mujeres que entrevistamos; cuando nos hablan de sus maternidades, de las miserias del desamor, de los deberes de cuidado impuestos por el género, las sentimos próximas. Pero nuestra posición hegemónica respecto a ellas, en tanto mujeres investigadoras del Norte global, independientemente del hemisferio geográfico en que se ubiquen -La Plata o A Coruña-, hace de las vivencias femeninas que compartimos, experiencias radicalmente distintas. La raza incorporada en el color claro de nuestras pieles y nuestros cabellos, mediatizada por nuestros pasaportes europeos, levanta una frontera entre nosotras y las mujeres que han dado vida con sus relatos a este texto.

El género es para estas mujeres (también para nosotras) la primera línea de demarcación de sus identidades. Categorizadas como "lo femenino" desde el momento de su nacimiento, un destino social se cierne sobre ellas (Rubin, 1989). El matrimonio y la responsabilidad de producir y reproducir la vida mediante el ejercicio de la maternidad y el trabajo de proveer cuidados a la familia y la comunidad son objetivos culturales que condicionan las experiencias de humanidad de todas y cada una de las migrantes entrevistadas.

Para las migrantes solitarias brasileñas y colombianas, la migración modifica las relaciones de poder al interior de los grupos domésticos (Tapia Ladino y González Torralbo, 2013). Reconocidas como proveedoras, las mujeres pasan a ocupar locus centrales en las jerarquías familiares; en este sentido, la migración también representa para las mujeres, una búsqueda de respeto para sí mismas. Para las mujeres bolivianas, en cambio, el hecho de encarnar un proyecto migratorio familiar las ubica en un lugar de dependencia económica y su trabajo -productivo y doméstico- no siempre es valorado como tal. 
El género de las mujeres bolivianas, brasileñas y colombianas permeará por completo sus trayectorias migratorias. Los/as hijos/as condicionarán irrevocablemente las experiencias de las madres. Darles mejores oportunidades educativas o alejarles del ambiente violento que impera en las desiguales urbes de Brasil y Colombia se vuelve prioritario para las migrantes en la Península Ibérica (Oso y Suárez-Grimalt, 2018). Para las bolivianas, el hecho de tener hijos y/o hijas socializados/as y educados/as en Argentina significa sacrificar el deseo de regresar al país de origen.

El matrimonio es para las migrantes solas una oportunidad de integración social en España y Portugal, pero también un nicho propicio para el desarrollo de un tipo muy particular de violencia en el que coluden elementos misóginos y racistas (Piscitelli, 2008). Las leyes migratorias contribuyen muchas veces al hecho de que estas mujeres no puedan existir como ciudadanas si no es en forma de "propiedad" de los hombres locales. Para las bolivianas, en cambio, la migración supone la concreción de un proyecto familiar. El matrimonio con alguien de la comunidad boliviana va asociado a la posibilidad de insertarse en destino, sobre todo para trabajar en una actividad que requiere la fuerza de trabajo de ambos cónyuges, como es la agricultura. Sin embargo, las redes comunitarias transnacionales que abren la posibilidad de migrar atrapan también a las mujeres, cuyos rasgos indígenas alienan las posibilidades de "conocer hombres" por fuera de este círculo, y quienes, además, en el aislamiento del ámbito rural quedan relegadas al lugar de madre y esposa.

La herencia colonial, plasmada en forma de marcas que se expresan en los cuerpos, en el lenguaje, en la cultura y en los imaginarios trazados sobre ellos reproduce formas de dominación que se actualizan a cada paso dado por las mujeres migrantes (Quijano, 2014; Segato, 2013). Las bolivianas son representadas en Argentina por medio de imágenes socioculturales que remiten a los Andes y al altiplano. Lo andino se constituye así como una categoría racial, que se manifiesta por medio de ideas que aluden al carácter rústico, tímido, predispuesto al trabajo duro, y se encarna y expresa en los trazos indígenas que se descubren sobre los cuerpos de las mujeres bolivianas (Canessa, 2008). Las migrantes colombianas y brasileñas, en cambio, son racializadas en España y Portugal de un modo muy distinto, casi opuesto, a través de una "latinidad tropicalizada" (Piscitelli, 2008). Representadas como seres mestizos en los que confluye lo blanco, lo negro y lo indio, colombianas y brasileñas son imaginadas bajo las mismas formas que las regiones de las que proceden, como relajadas, calientes y exuberantes. Esta incorporación de la naturaleza y el clima presupuestos a los territorios de origen, en el carácter físico y psíquico-moral de las mujeres, es una estrategia de subhumanización, que aleja a bolivianas, brasileñas y colombianas del individuo racional, sujeto de derecho de la Modernidad (Lugones, 2008).

Estos imaginarios racializados organizan eficientemente la división sexual y racial del trabajo, precisamente porque vienen a reafirmar identidades subordinadas ("ser puta", "ser burra"), que comienzan a ser producidas en los propios territorios de origen de las mujeres. Desvalorizarse, considerarse inferior, no sentirse capaz o aceptar situaciones humillantes y/o violencias forma parte de los modos en que estas identidades son puestas en práctica e internalizadas, 
a veces inconscientemente. Esto viene a constatar la existencia de un discurso hegemónico que para las mujeres resulta difícil de confrontar.

Al mismo tiempo, maniobrando estas identidades peyorativas, las mujeres van resignificando su camino y apropiándose de su singularidad, desplegando distintas formas de resistencia, en las que se reinventan a sí mismas. Las migrantes brasileñas y colombianas utilizan la hipersexualidad para posicionarse mejor en los mercados laborales y matrimoniales (Hurtado Sáa, 2018; Piscitelli, 2011; Pravaz, 2012); mientras las bolivianas, a través de la autoexplotación, se revalorizan como trabajadoras (en detrimento de las trabajadoras locales), y consiguen mejorar económicamente a costa de este sacrificio.

\section{Conclusiones}

Estas notas apuntan a la necesidad de tomar la colonialidad y la interseccionalidad como ejes analíticos clave en la comprensión de los fenómenos migratorios Sur/Norte contemporáneos. Las estructuras materiales y simbólicas forjadas durante el colonialismo en Iberoamérica siguen organizando en múltiples maneras y grados, aun después de la descolonización oficial del mundo, la política, la economía y las representaciones culturales (De Sousa Santos, 2014). La interseccionalidad nos permite abordar, en este orden postcolonial de las cosas, los significados particulares que asumen las categorías de género, raza y clase en cada contexto, configurando diferentes identidades y trayectorias migratorias para las mujeres del Sur en el Norte. A partir del análisis comparado de estas trayectorias, rastreamos los modos en que la raza, a través de la nacionalidad y el género, se constituye en reciprocidad para dar lugar a cierta clase de trabajadoras: putas, criadas y campesinas (Lugones, 2008; Nagel, 2003).

Consideramos que uno de los principales aportes de este ejercicio de investigación tiene que ver con poner en valor la perspectiva interseccional y postdecolonial como marco epistemológico para analizar procesos de migración internacional, basados en evidencia empírica cualitativa. Las historias de vida de las migrantes del sur, sus padecimientos, sus logros y sus anhelos nos hablan de la reminiscencia de las formas de dominación colonial, que se entrelazan en las atribuciones de sentido, en las identidades raciales y de género que emergen en el espacio social migratorio.

\section{Referencias}

Actis, W. (2009) La migración colombiana en España: ¿̇salvados o entrampados? Revista de Indias, 2009, LXIX(245),145-170, ISSN: 0034-8341.

Agarwal, B. (2002). Are we not peasants too? Land rights and women's claims in India. Seeds, 21, 1-30.

Ambort, M. E. (2019). Género, trabajo y migración en la agricultura familiar. Análisis de las trayectorias familiares, laborales y migratorias de mujeres agricultoras en el cinturón hortícola de La Plata (1990-2019). FLACSO.

Anderson, B. (2015). Migrant Domestic Workers: Good Workers, Poor Slaves, New Connections. Social Politics, 22(4), 636-652.

Aparicio, F. R. \& Chávez-Silverman, S. (1997). Tropicalizations: Transcultural Representations of Latinidad. University Press of New England. 
Ataide, S. (2015). Trayectorias, redes migratorias y procesos identitarios, en la conformación del mercado de trabajo agricola destinado a bolivianos. Estudio en dos municipios del este salteño (1960-2013). FLACSO.

Benencia, R. (2005). Migración limítrofe y mercado de trabajo rural en la Argentina. Estrategias de familias bolivianas en la conformación de comunidades transnacionales. Revista Latinoamericana de Estudios Del Trabajo, 10(17), 5-30.

Bourdieu, P. (2000). Cuestiones de sociología. Madrid: Istmo.

Bourdieu, P. (2003). El oficio de cientifico. Ciencia de la ciencia y reflexividad. Barcelona: Editorial ANAGRAMA.

Canessa, A. (2008). El sexo y el ciudadano: Barbies y reinas de belleza en la era de Evo Morales. En P. Wade, F. Urrea Giraldo, y M. Viveros Vigoya (Eds.), Raza, etnicidad y sexualidades. Ciudadania y multiculturalismo en América Latina, 69-104. Bogotá: Universidad Nacional de Colombia.

Cassanello, C. A. (2014). Historia reciente de los inmigrantes bolivianos en la Argentina, 1970-2000 Trayectorias migrantes, redes sociales y transnacionalidad. Universidad Nacional de Quilmes.

Crenshaw, K. (1991). Mapping the margins: Intersectionality, Identity Politics and Violence against women of Color. Stanford Law Review. 43(6), 1241-1297.

De Sousa Santos, B. (2014). Epistemologias del Sur. Madrid: Akal.

Deere, C. D. (1982). La mujer rural y la producción de subsistencia en la periferia capitalista. En M. León (Ed.), DEBATE SOBRE LA MUJER EN AMERICA LATINA Y EL CARIBE: Discusión acerca de la Unidad Producción-Reproducción. Vol. II Las trabajadoras del agro, 11-22. Bogotá: ACEP.

Ehrenreich, B., y Hochschild, A. R. (2003). Global Woman: Nannies, Maids, and Sex Workers in the New Economy. London: Granta books.

Federici, S. (2013). Revolucio\#n en punto cero: trabajo doméstico, reproducción y luchas feministas. Madrid: Traficantes de Sueños.

França, T., y Padilla, B. (2018). Imigração brasileira para Portugal: entre o surgimento e a construção mediática de uma nova vaga. Cadernos de estúdios sociais. 33(2), 1-30.

García, M. (2011). Proceso de acumulación de capital en campesinos. El caso de los horticultores bolivianos de Buenos Aires (Argentina). Cuadernos de Desarrollo Rural, 8(66), 47-70.

González Torralbo, H. (2016). Las familias transnacionales ¿̇una tautología? Más allá de la dicotomía "distancia/proximidad geográfica". Polis. Revista Latinoamericana, 15(43), 511-532.

Gregorio Gil, C. (2019). Explorar posibilidades y potencialidades de una etnografía feminista. Disparidades. Revista de Antropología, 74(1), 1-7.

Gregorio, C. (2017). Etnografiar las migraciones 'Sur'-'Norte': la inscripción en nuestros cuerpos de representaciones de género, raza y nación. EMPIRIA. Revista de Metodología de Ciencias Sociales, 37, 19-39.

Grimson, A. (2006) Nuevas xenofobias, nuevas políticas étnicas en Argentina. En Grimson, A. y E. Jelin (Eds.), Migraciones regionales hacia la Argentina. Diferencia, desigualdad y derechos, 69-99. Buenos Aires: Prometeo.

Grosfoguel, R., y Maldonado Torres, N. (2008). Los latinos, los migrantes y la descolonización del imperio estadounidense en el siglo XXI. University of California, Berkeley.

Hill Collins, P. (2017). The Difference That Power Makes: Intersectionality and Participatory Democracy. Investigaciones Feministas, 8(1), 19-39. 
Hill Collins, P., \& Bilge, S. (2016). Intersectionality. Cambridge: Polity.

Hurtado Sáa, T. (2018). La producción social del mercado del sexo en España y de la ocupación d trabajadoras sexuales en España. Revista Colombiana de Antropología, 54(2), 35-58.

Lugones, M. (2008). Colonialidad y género. Tabula Rasa, 9, 73-101.

Magliano, M. J. (2009). Migración, género y desigualdad social. La migración de mujeres bolivianas hacia Argentina. Revista Estudos Feministas, 17(2), 349-367.

Magliano, M. J. (2015). Interseccionalidad y migraciones: Potencialidades y desafíos. Revista Estudos Feministas, 23(3), 691-712.

Malheiros, J., \& Padilla, B. (2015). Can stigma become a resource? The mobilisation of aesthetic-corporal capital by female immigrant entrepreneurs from Brazil. Identities, 22(6), 687-705.

Mallimaci, A. I. (2012). Revisitando la relación entre géneros y migraciones. Resultados de una investigación en Argentina. Mora, 18(2), 151-166.

Martínez-Buján, R. (2014). ¡El trabajo doméstico cuenta! Características y transformaciones del servicio doméstico en España. Migraciones, 36(2), 275-305.

Mezzadra, S., y Nielson, B. (2013). Border as method, or, the multiplication of labor. Durham, North Carolina: Duke University Press.

Nagel, J. (2003). Race, ethnicity and sexuality. Intimate intersections, forbidden frontiers. Oxford, U.K: Oxford University Press.

Neiman, G., y Quaranta, G. (2006). Los estudios de caso en la investigación sociológica. En I. Vasilachis de Gialdino (Ed.), Estrategias de investigación cualitativa, 213-237. Buenos Aires: Gedisa.

Oso, L., \& Catarino, C. (2013). From Sex to Gender: The Feminisation of Migration and Labour-Market Insertion in Spain and Portugal. Journal of Ethnic and Migration Studies, 9(4), 625-647.

Oso, L., y Parella, S. (2012). Inmigración, género y Mercado de trabajo: una panorámica de la investigación sobre la inserción Laboral de las mujeres inmigrantes en España. Cuadernos de Relaciones Laborales, 30(1), 11-44.

Oso, L., y Suárez-Grimalt, L. (2018). Towards a theoretical model for the study of productive and reproductive strategies in transnational families: Latin American migration and social mobility in Spain. Journal of Family Studies, 24(1), 41-58.

Pedone, C. (2010). Cadenas y redes migratorias: propuesta metodológica para el análisis diacrónico-temporal de los procesos migratorios. Empiria, 19, 101-132.

Pérez Orozco, A. (2014). Subversión feminista de la economia. Aportes para un debate sobre el conflicto capital-vida. Madrid: Traficantes de sueños.

Piscitelli, A. (2007). Confronting corporalities: Brazilian women in the transnational sex industry. Revista Brasileira de Ciencias Sociais. 22(64), 17-32.

Piscitelli, A. (2008). Interseccionalidade, categorias de articulac\#a\#o e experie\#ncias de migrantes brasileñas. Sociedade e Cultura, 11(2), 263-274.

Piscitelli, A. (2011) Performing Brazilianness? Displacements from the sex market. Etnográfica, 15(1), 5-29.

Pizarro, C. (2011). Inmigrantes bolivianos en el sector hortícola. Entre la discriminación racializante, la precariedad laboral y la movilidad socio-productiva. En C. Pizarro (Ed.), "Ser boliviano" en la región metropolitana de la ciudad de Córdoba. (pp. 119-164). Córdoba: EDUCC Editorial de la Universidad Católica de Córdoba.

Portes, A. (2009). Migración y cambio social: algunas reflexiones conceptuales Migration and social change: some conceptual reflections. RES, 12, 9-37. 
Pravaz, N. (2012). Performing Mulata-ness: The Politics of Cultural Authenticity and Sexuality among Carioca Samba Dancers. Latin American Perspectives, 39(2) 113-133.

Quijano, A. (2014). Colonialidad del poder, eurocentrismo y Ame\#rica Latina. Buenos Aires: CLACSO.

Reygadas, L. (2004). Las redes de la desigualdad: un enfoque multidimensional. Politica $y$ Cultura, 22, 7-25.

Rubin, G. (1986). El tráfico de mujeres: notas sobre la economía política del sexo. Nueva Antropología, 8(30), 95-145.

Sassen, S. (2003). Contrageografías de la globalización. Género y ciudadania en los circuitos transfronterizos. Madrid: Traficantes de sueños.

Sayad, A. (1996). La double absence: des illusions de l'émigré aux souffrances de l'immigré. Paris: Seuil.

Segato, R. L. (2013). La cri\#tica de la colonialidad en ocho ensayos: y una antropologi\#a por demanda. Buenos Aires: Prometeo.

Tapia Ladino, M., y González Torralbo, H. (2013). Me voy a España a trabajar... familias migrantes colombianas, remesas económicas y relaciones de género en un contexto transnacional. Chungara, Revista de Antropologia Chilena, 45(2), 333-347.

Vélez de Castro, F., y Cravidão, F. (2010). Cais de chegada: a imigração no contexto ibérico; uma análise comparativa. Polígonos. Revista de Geografía, 20, 147-169.

Wade, P. (2003). Repensando el mestizaje. Revista Colombiana de Antropología, 39, 273-296.

Wallerstein, I. (1997). La reestructuración capitalista y el sistema-mundo. México: XX Congreso de la Asociación Latinoamericana de Sociología.

Winker, G., \& Degele, N. (2011). Intersectionality as multi-level analysis: Dealing with social inequality. European Journal of Women Studies, 128(1), 51-66.

\section{Notas}

1 Siglas en inglés para Red Internacional para el Análisis Comparado de la Desigualdades Sociales (International Network for Comparative Analysis of Social Inequalities) https:/ /incasi.uab.cat/. Parte del artículo ha sido elaborado en el contexto de INCASI, Marie Słodowska-Curie, GA No. 691004, coordinado por Pedro López-Roldán. El artículo refleja los puntos de vista de las autoras. Las agencias no son responsables por el uso de la información que contiene.

2 Boaventura de Sousa Santos (2014) da a los términos Sur y Norte un sentido metafórico, que excede lo geográfico. Sur y Norte hacen referencia a dos espacios diferenciados entre los que los desequilibrios económicos, sociales y políticos abren una frontera que divide las vidas de los privilegiados y los subordinados por las estructuras capitalistas.

3 Datos Instituto Nacional de Estadística (España) y Serviço de Estrangeiros e Fronteiras (Portugal).

4 Según el Censo de Población y Vivienda de 2012 casi el 40\% de la emigración boliviana reside en Argentina. Instituto Nacional de Estadística (Bolivia). 